\title{
Estimation of colored dissolved organic matter and salinity fields in case 2 waters using SeaWiFS: Examples from Florida Bay and Florida Shelf
}

\author{
E J D'SA ${ }^{1}, \mathrm{C} \mathrm{Hu}^{2}, \mathrm{~F}$ E Muller-Karger and K L Carder \\ College of Marine Science, University of South Florida, St. Petersburg, FL 33701, USA \\ ${ }^{1}$ Present address: GB Tech, NASA Earth Science Applications Directorate, Bldg. 1100, \\ Stennis Space Center, MS 39529, USA \\ e-mail: ejdsa@ssc.nasa.gov \\ ${ }^{2} h u @ s e a s . m a r i n e . u s f . e d u$
}

\begin{abstract}
Estimates of water quality variables such as chlorophyll $a$ concentration (Chl), colored dissolved organic matter (CDOM), or salinity from satellite sensors are of great interest to resource managers monitoring coastal regions such as the Florida Bay and the Florida Shelf. However, accurate estimates of these variables using standard ocean color algorithms have been difficult due to the complex nature of the light field in these environments. In this study, we process SeaWiFS satellite data using two recently developed algorithms; one for atmospheric correction and the other a semianalytic bio-optical algorithm and compare the results with standard SeaWiFS algorithms. Overall, the two algorithms produced more realistic estimates of $\mathrm{Chl}$ and CDOM distributions in Florida Shelf and Bay waters. Estimates of surface salinity were obtained from the CDOM absorption field assuming a conservative mixing behavior of these waters. A comparison of SeaWiFS-derived Chl and CDOM absorption with field measurements in the Florida Bay indicated that although well correlated, CDOM was underestimated, while Chl was overestimated. Bottom reflectance appeared to affect these estimates at the shallow central Bay stations during the winter. These results demonstrate the need for new bio-optical algorithms or tuning of the parameters used in the bio-optical algorithm for local conditions encountered in the Bay.
\end{abstract}

\section{Introduction}

Florida Shelf and Florida Bay are important coastal regions where water quality monitoring is of interest due to a variety of factors such as algal die-offs, increased phytoplankton abundance, harmful algal blooms and a perceived decline in fisheries (Tilmant 1989; Phlips and Badylak 1996; Boyer et al 1999; Fourqurean and Robblee 1999). Spatial and temporal variability in the bio-optical constituents (e.g., Chl) affecting water quality necessitates regular and synoptic monitoring that can be achieved only by remote sensing techniques. Ocean color data from the
Sea-viewing Wide Field-of-view Sensor (SeaWiFS, Hooker et al 1992) are being used to derive estimates of products such as chlorophyll in oceanic waters. The two major steps involved in processing remotely sensed ocean color satellite data are the application of atmospheric correction to remove the atmospheric contribution to the radiance measured by the satellite sensor, and the use of bio-optical algorithms that relate water-leaving radiance to the in-water constituents. Although the application of standard remote sensing algorithms have shown successes in case 1 or open ocean waters, they have not been successful in accurately estimating bio-optical variables such as

Keywords. Remote sensing; SeaWiFS; atmospheric correction; chlorophyll a; CDOM; salinity. 
$\mathrm{Chl}$ in coastal or case 2 waters. The main reasons are that

- atmospheric correction is interfered by case 2 water constituents, and

- the co-varying relationship between $\mathrm{Chl}$ and other optical constituents for case 1 waters may not be applicable to case 2 waters (Morel and Prieur 1977; Carder et al 1991).

The atmosphere usually contributes more than $80 \%$ of the signal measured by an ocean color satellite sensor. The atmospheric correction procedure (Gordon and Wang 1994) seeks to remove this contribution from the sensor signal in order to retrieve the water-leaving radiance. The total radiance $L_{t}(\lambda)$ or reflectance $\rho_{t}(\lambda)$ (where $\rho_{t}(\lambda)=$ $\pi L_{t}(\lambda) /\left(F_{0}(\lambda) \mu_{0}\right)$, and $F_{0}(\lambda)$ is the extraterrestrial solar irradiance and $\mu_{0}$ is the cosine of the solar zenith angle) observed by the sensor at wavelength $\lambda$, is the sum due to Rayleigh scattering $\rho_{r}(\lambda)$, the aerosol scattering $\rho_{a}(\lambda)$ (includes the aerosol-Rayleigh interaction term) and $\rho_{w}(\lambda)$, the reflectance from the water column. This can be written as

$$
\rho_{t}(\lambda)=\rho_{r}(\lambda)+\rho_{a}(\lambda)+t(\lambda) \rho_{w}(\lambda) .
$$

The term $t(\lambda)$ is for the diffuse transmittance from the target to the sensor. While $\rho_{r}(\lambda)$ can be accurately calculated (Gordon et al 1988), $\rho_{a}(\lambda), t(\lambda)$, and $\rho_{w}(\lambda)$ are unknowns to be determined. The SeaWiFS algorithm makes an assumption of zero $\rho_{w}(\lambda)$ in the near-infrared part of the spectrum enabling $\rho_{a}(765)$ and $\rho_{a}(865)$ to be computed. Ratios of these two values are used to select an aerosol type and an aerosol optical depth in the near-infrared. Based on the aerosol model selected, the optical depth is extrapolated to the visible wavebands. In case 2 waters however, high concentrations of organic and inorganic suspended matter may cause the water-leaving signal in the near infrared to be significantly greater than zero (Arnone et al 1998; D'Sa et al 2000; Ruddick et al 2000; Hu et al 2000, 2001). As a result, the aerosol optical thickness that is derived from this signal in the near infrared, may be overestimated and further propagated to an "overcorrection" in the visible part of the spectrum. The problem of zero water-leaving radiance in the near-infrared or the black pixel assumption has been addressed through iterative approaches for SeaWiFS data processing (Arnone et al 1998; Siegel et al 2000) and have shown improvements in obtaining more realistic estimates of Chl in turbid coastal waters. The iterative approach of Siegel et al 2000 (now included in the SeaWiFS processing software-SeaDAS V4.1) assumes some fixed relationship between $\mathrm{Chl}$ and water-leaving radiance in Bands 6, 7, and 8. This assumption may not be applicable for turbid coastal waters where the optical properties may be dominated by other constituents or the shallow bottom, not by Chl. In contrast, another approach to correct for the effect of the near-infrared contribution of water-leaving radiance to the atmospheric correction is to transfer an aerosol type of the nearest less turbid waters to the turbid water pixels ( $\mathrm{Hu}$ et al 2000). In this study we apply the turbid water correction $(\mathrm{Hu}$ et al 2000) to SeaWiFS data of the Florida Shelf and the Florida Bay and compare the results to the atmospheric correction schemes used in the standard SeaWiFS data processing.

Ocean color bio-algorithms used in processing SeaWiFS data use empirical relationships between band ratios of remote sensing reflectances and $\mathrm{Chl}$ to obtain estimates of Chl (O'Reilly et al 1998). These empirical relationships are based on the assumption that variations in ocean color optical signal is determined mainly by phytoplankton pigments. However, in coastal waters other oceanic constituents that include suspended matter and CDOM can also contribute significantly to the optical signal (Tassan 1994). The semianalytic algorithms (Garver and Siegel 1997; Carder et al 1999) have been developed mainly through improved knowledge of the in-water bio-optical properties and the relationships between remote sensing reflectance and backscattering to absorption ratios (O'Reilly et al 1998). In this study we use the Carder semianalytic algorithm (Carder et al 1999) to derive Chl and CDOM absorption at $400 \mathrm{~nm}\left(a_{g} 400\right)$, for a coastal region.

The two recently developed atmospheric correction ( $\mathrm{Hu}$ et al 2000) and bio-optical algorithms (Carder et al 1999) have shown promising results with retrieval of oceanic constituents from SeaWiFS. In this work, we further test and present results using these algorithms to estimate $\mathrm{Chl}$ and CDOM, two water quality parameters of interest in the Florida Bay and the Florida Shelf. These results are then compared with those from the standard algorithms that have been used for SeaWiFS data processing. Using measured CDOM absorption-salinity relationship we then generate sea surface salinity images from CDOM absorption estimates derived from the remote sensing data.

\section{Methods}

The standard atmospheric correction scheme used in this study combines the Gordon and Wang (1994) and Ding and Gordon (1995) algorithms that are incorporated in the NASA standard 
processing software (SeaDAS V4.1). Further, we also process the SeaWiFS data over Florida Bay using the Siegel iterative approach to deal with the non-black pixel problem. The atmospheric correction procedure of $\mathrm{Hu}$ et al (2000) used in this study provides a practical method to separate the water-column reflectance from the total reflectance at 765 and $865 \mathrm{~nm}$ over turbid coastal waters. Based on an initial identification of turbid pixels, the aerosol type defined over a nearby, nonturbid region is transferred to the turbid area by using a "nearest neighbor" method. It is based on the assumption that the type of aerosol does not vary much over relatively small spatial scales $(\sim 50-100 \mathrm{~km})$. The selection of an appropriate aerosol type for the turbid pixel from a neighboring non-turbid pixel, enables the aerosol reflectance and the water-column reflectance at 765 and 865 $\mathrm{nm}$ to be derived. Subsequently, the default NASA atmospheric correction scheme is used to obtain aerosol scattering components at visible wavelengths.

After applying atmospheric correction to the atsensor measured radiances, different approaches are used to determine oceanic constituents from the resulting normalized water leaving radiances $\left(n L_{w}(\lambda)\right)$. The two-band ratio or OC2 algorithm (O'Reilly et al 1998) used to estimate Chl $\left(\mathrm{mg} \mathrm{m}^{-3}\right)$ is given by the relation:

Chl $=0.0929+10^{\left(0.2974-2.2429 X+0.8358 X^{*} X-0.0077 X^{*} X^{*} X\right)}$

where $X=\log (\operatorname{Rrs} 490 / \operatorname{Rrs} 555)$ and Rrs (remote sensing reflectance) is defined as $n L_{w} / F_{0}\left(F_{0}\right.$ is the solar constant). For the specific case of Florida Bay, we process the SeaWiFS data using the Ocean Color OC4 bio-optical algorithm. The current version of OC4 is a four-band maximum band ratio formulation (O'Reilly et al 2000) and uses a fourth order polynomial (five coefficients) to estimate Chl and is given by:

$$
\mathrm{Chl}=10.0^{(0.366-3.067 X+1.930 X 2+0.649 \times 3-1.532 X 4)}
$$

where $\quad X=\log (\operatorname{Rrs} 443 / \operatorname{Rrs} 555>\operatorname{Rrs} 490 / \operatorname{Rrs} 555$

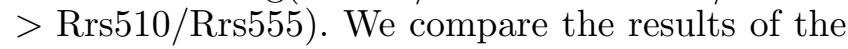
band ratio algorithms to the Carder semianalytic algorithm (Carder et al 1999) that uses both analytical and empirical formulae in conjunction with the remote sensing reflectance values at five bands $(412,443,490,510$ and $555 \mathrm{~nm})$ to derive the absorption coefficient of phytoplankton at $675 \mathrm{~nm}$, $a_{\mathrm{ph}}(675)$ and the absorption coefficient of CDOM at $400 \mathrm{~nm}$. An empirical relationship between $\mathrm{Chl}$ and $a_{\mathrm{ph}}(675)$ is then used to estimate Chl.
We evaluate these algorithms over the coastal region of the Florida Shelf and further compare the results with in situ measurements in the Florida Bay. Florida Bay is located at the southern tip of the Florida Peninsula, United States and is a unique subtropical estuary that has seen many ecological changes to its ecosystem (Fourqurean and Robblee 1999). The climate in Florida Bay is characterized by a relatively warm wet season from May to October and a cooler dry season from November to April. Data from two field measurements conducted in October 1997 and January 1998 are compared to SeaWiFS derived variables using a combination of atmospheric and bio-optical algorithms. Chl and phaeopigment concentrations were determined using fluorometric method (Parsons et al 1984). A $0.5 \mathrm{~m}$ long capillary waveguide system was used to measure spectral absorption coefficient of CDOM (D'Sa et al 1999). Surface salinity was measured using an airborne scanning low frequency microwave radiometer (D'Sa et al 2000; Le Vine et al 2000; D'Sa et al 2002). A Secchi disk was used to measure water clarity. The field stations were along two transects at the western and central Bay regions (location of stations shown as triangles in figures $4 \mathrm{a}$ and $4 \mathrm{~b}$ ).

\section{Results and discussion}

In figures 1(a) and 1(b) we show results of $\mathrm{Chl}$ estimates from SeaWiFS data of 18th October 1999, obtained using two atmospheric correction schemes (Gordon and Wang 1994; Hu et al 2000) and the same bio-optical algorithm (OC2). We observe two main differences. With the default NASA algorithm (Hooker et al 1992; McClain et al 1995) a large region in the Bay that has been masked due to "atmospheric-correction failure" and "negative water-leaving radiance" flags (dark region) have been evaluated for Chl by the "nearest neighbor" correction algorithm (figure 1b). Also, generally higher Chl estimates have been obtained by the default NASA algorithm in comparison to the coastal algorithm. We then applied the Carder semianalytic algorithm to the water-leaving radiance spectra obtained with the "nearest neighbor" atmospheric correction algorithm. The SeaWiFS image (figure 1c) shows high CDOM levels in the Bay and was indicative of the flooding that occurred after Hurricane Irene (15th October 1999). Salinity field (figure 1d) derived from CDOM estimates also shows features due to coastal runoff in the Bay and West Florida Shelf.

Various field measurements have indicated a conservative mixing or dilution behavior for the 

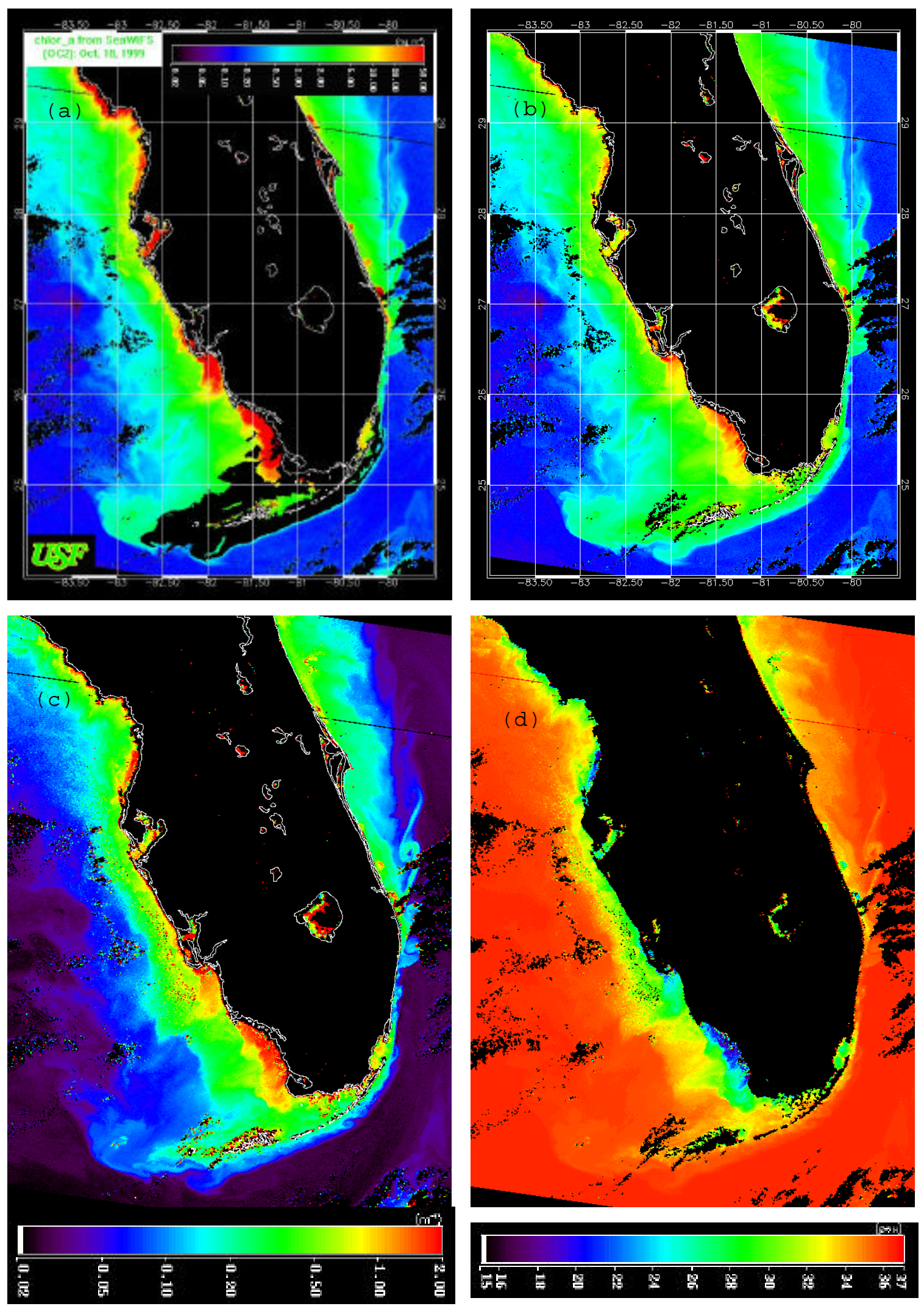

Figure 1. (a) Chl $\left(\mathrm{mg} \mathrm{m}^{-3}\right)$ derived from SeaWiFS data obtained on 18th October 1999 using NASA default atmospheric correction and OC2 algorithm, (b) Chl derived from the same SeaWiFS data using the "nearest neighbor" atmospheric col tion and OC2 algorithm, (c) CDOM absorption $a_{g} 400\left(\mathrm{~m}^{-1}\right)$ using the "nearest-neighbor" atmospheric correction an arder semianalytic algorithm, and (d) sea surface salinity image derived from (c) using measured CDOM absorption-salinity relationship. 

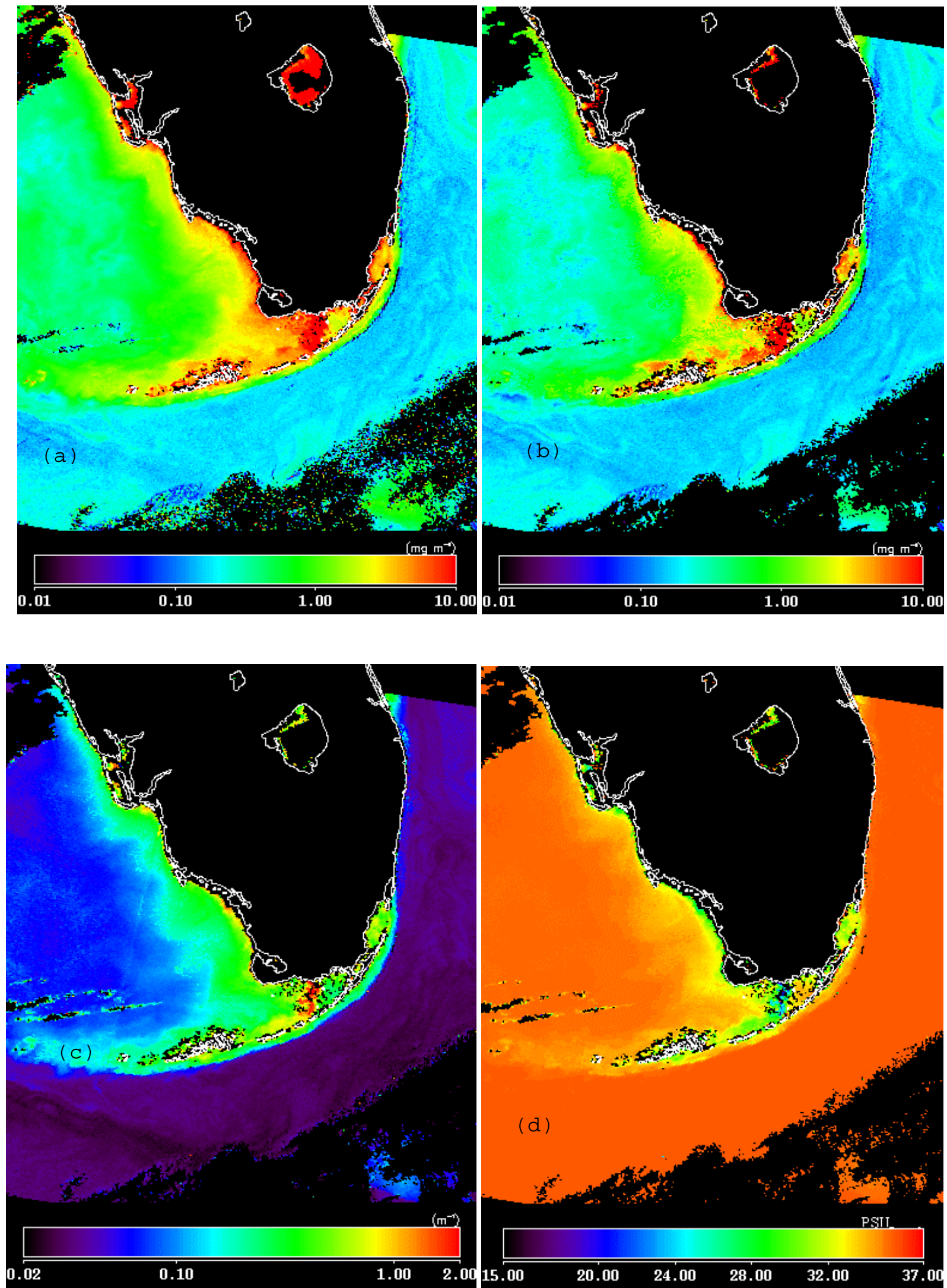

Figure 2. (a) SeaWiFS image of $\mathrm{Chl}\left(\mathrm{mg} \mathrm{m}^{-3}\right)$ acquired on 24th February 1999 and processed using the NASA atmospheric correction and $\mathrm{OC} 2$ algorithm, (b) Chl derived from the same data using the "nearest neighbor" correction algorithm and Carder semianalytic algorithm, (c) CDOM image computed using Carder's semianalytic algorithm, and (d) salinity image derived from $a_{g} 400$. 

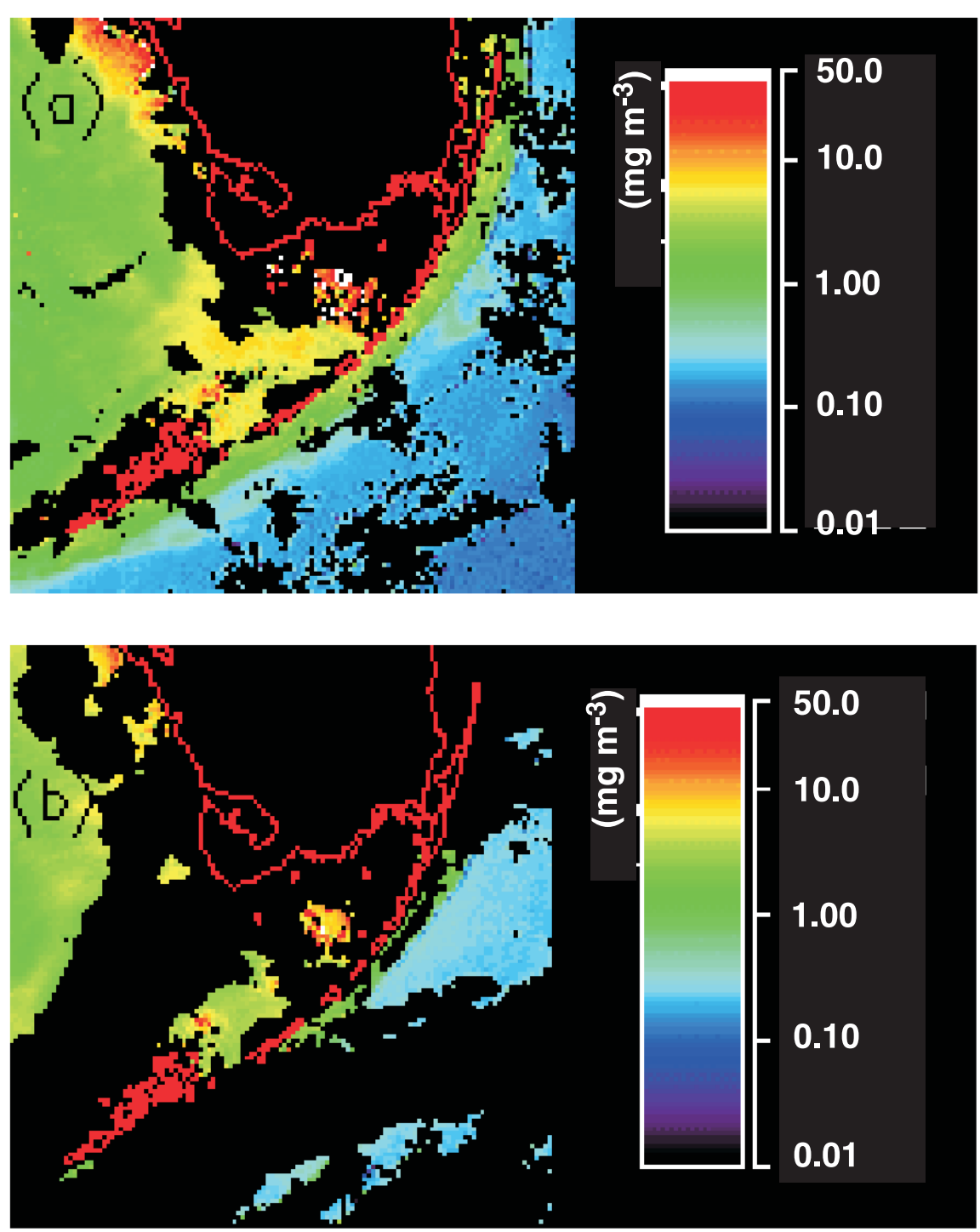

Figure 3. SeaWiFS images of Chl $\left(\mathrm{mg} \mathrm{m}^{-3}\right)$ acquired on (a) 4th October 1997 and (b) 31st January 1998 and processed using the NASA atmospheric correction, the Siegel near-infrared iterations and the OC4 bio-optical algorithms.

optical properties of the dissolved material permitting derivation of the salinity field from the optical field (Blough et al 1993; D'Sa et al 2000; $\mathrm{Hu}$ et al 2002). A relationship between sea surface salinity (SSS) and CDOM absorption at 400 $\mathrm{nm} \quad\left(\mathrm{SSS}=35.71-6.954 \times a_{g} 400\right)$ was found from field measurements (Jennifer Patch, USF, personal comm.) and was used to derive SSS maps from satellite data (figure 1d). Similarly, correlation between CDOM and sea surface salinity in the continental margin of NE Gulf of Mexico was reported to be consistently high $\left(r^{2} \sim-0.85\right.$ or higher for $>7500$ data points), suggesting it can be used effectively to obtain salinity estimates from satellite data (Hu et al 2002). Figure 2(a) shows the $\mathrm{Chl}$ estimates obtained with the default NASA algorithm, while figure 2(b) shows Chl estimates obtained with the "nearest neighbor" correction and Carder semianalytic algorithm applied to a SeaWiFS image of 24th February 1999. We again observe lower Chl estimates for both coastal and offshore regions of the Bay and Shelf. CDOM absorption at $400 \mathrm{~nm}$ was further determined (figure 2c) using the semianalytic algorithm and salinity field derived (figure 2d) from the absorption image.

Figures 3(a) and 3(b) correspond to two SeaWiFS images of 4th October 1997 and 31st January 1998 processed with SeaWiFS processing software (SeaDAS V4.1) for the Florida Bay region. Field data obtained during the above days correspond to a generally warm wet season (May to October) and a cooler dry season (November to April). Sea surface salinity and in situ bio-optical variables (Chl, CDOM absorption, Secchi depth) were obtained along two transects (field stations shown as triangles in figures $4 \mathrm{a}$ and $4 \mathrm{~b}$ ) at the western and central regions of the Bay (D'Sa et al 

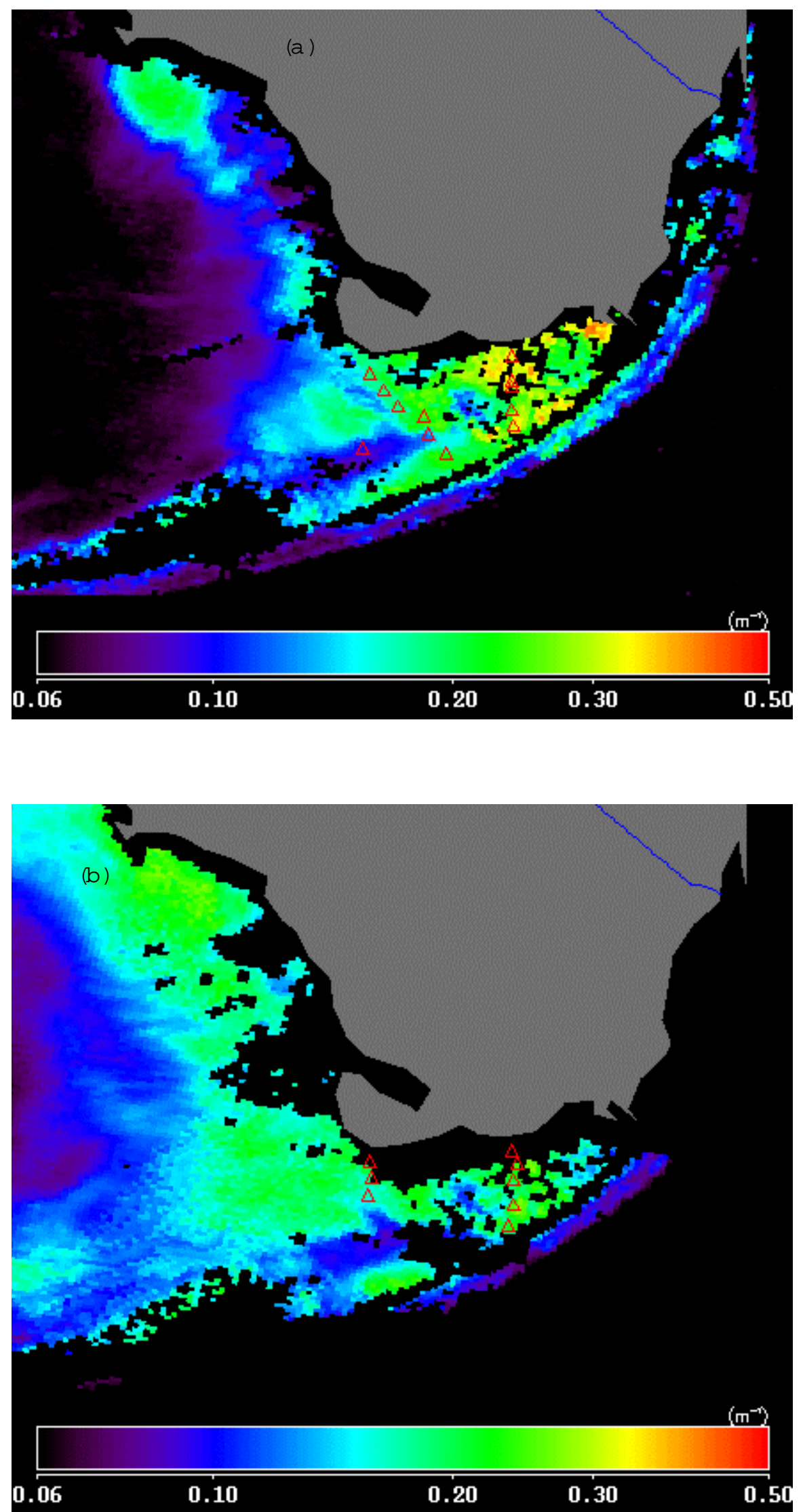

Figure 4. CDOM absorption field at $400 \mathrm{~nm}$ derived for the SeaWiFS image of (a) 4th October 1997 and (b) 31st January 1998 and computed using the "nearest neighbor" correction algorithm and Carder semianalytic algorithm. 

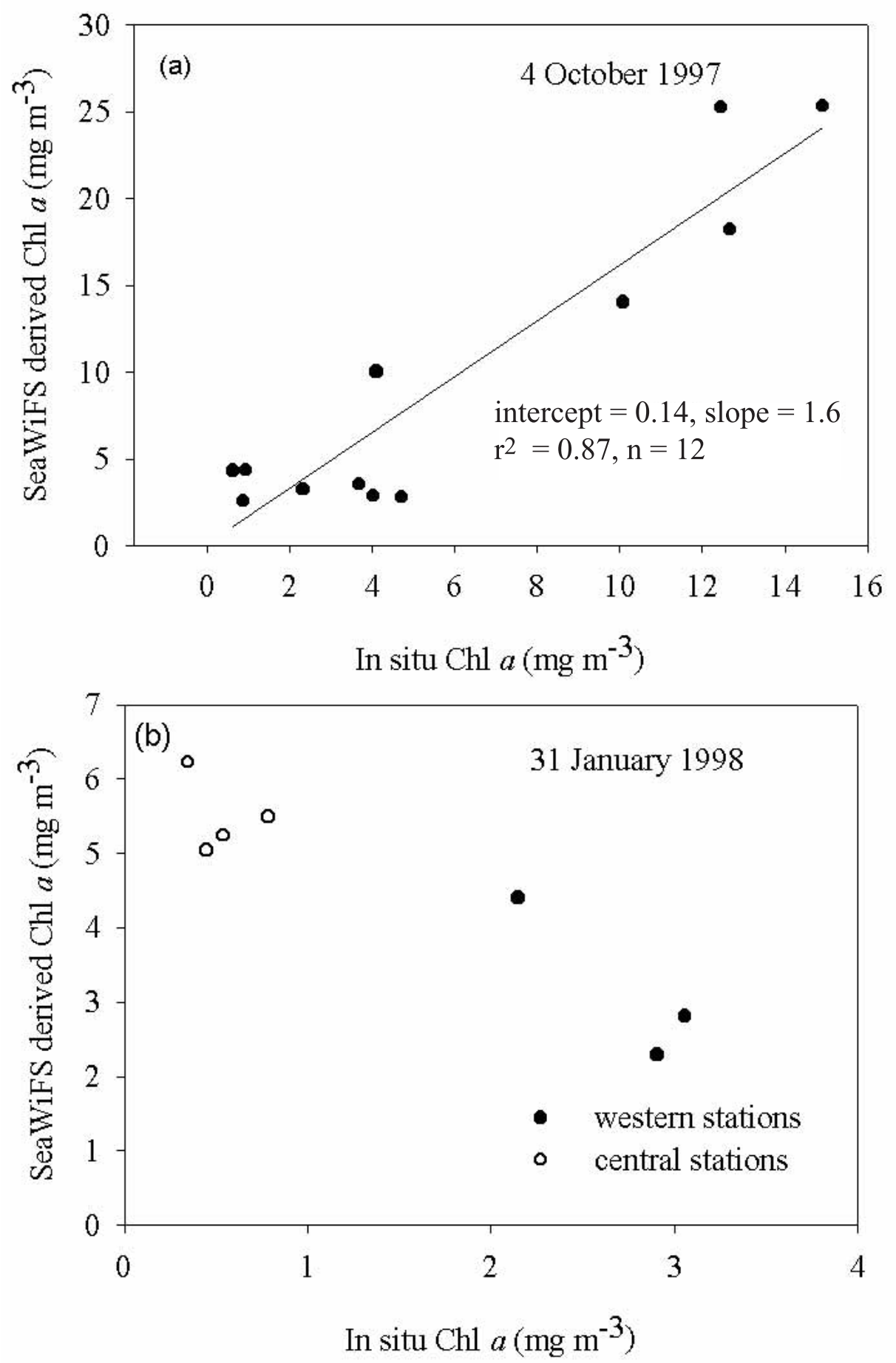

Figure 5. A comparison of Chl derived from (a) 4th October 1997 and (b) 31st January 1998 SeaWiFS data versus in situ measurements at stations in the Florida Bay shown in figures 4(a and b) (triangles). The SeaWiFS data were processed using the "nearest neighbor" correction algorithm and Carder semianalytic algorithm.

2002). The Gulf of Mexico influences the western region of the Bay, while the central Bay is a hydrographically isolated area influenced by terrestrial freshwater inputs (Boyer et al 1999). The range in $\mathrm{Chl}$ distributions ( 0.88 to $6.5 \mathrm{mg} \mathrm{m}^{-3}$ ) along the western transect were similar during the two seasons and generally increased at stations to the north. However, at the central stations the range of high $\mathrm{Chl}$ concentrations (4.6 to $14.9 \mathrm{mg} \mathrm{m}^{-3}$ ) observed in October 1997 were 

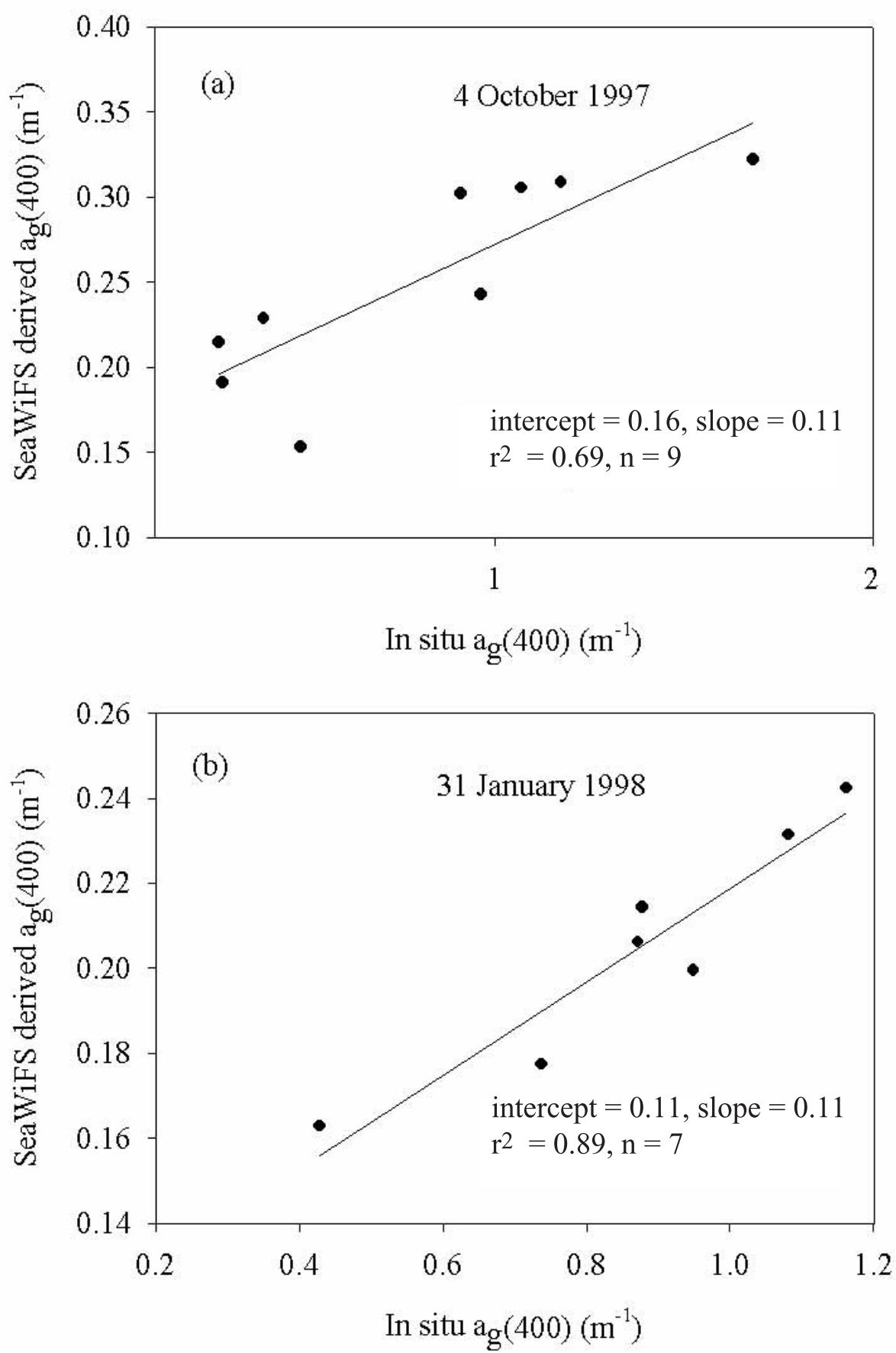

Figure 6. A comparison of SeaWiFS-derived CDOM absorption at $400 \mathrm{~nm}$ of (a) 4th October 1997 and (b) 31st January 1998 versus in situ measurements at stations shown in figures 4(a and b) (triangles). The SeaWiFS data were processed using the "nearest neighbor" correction algorithm and Carder semianalytic algorithm. The solid line is a linear regression fit for the estimated and measured CDOM absorption data. The coefficient of determination $\left(r^{2}\right)$, intercept and slope are given.

absent in January 1998 (0.5 to $\left.0.9 \mathrm{mg} \mathrm{m}^{-3}\right)$. This resulted in the Secchi disk being visible at the bottom for all the stations in the central region. Bottom reflectance would thus obviously affect the remote sensing signal in this region. CDOM absorption was generally higher at the central stations and increased to the north due to terrestrial inputs.
The SeaWiFS derived Chl images (figures $3 \mathrm{a}$ and $3 \mathrm{~b})$ were obtained using the atmospheric correction scheme (Gordon and Wang 1994), the Siegel iterative approach, and the OC4 band ratio algorithm. We observe a larger fraction of the Chl pixels being retrieved in the October (figure 3a) than the January image (figure 3b), although most pixels corresponding to the location of the field 
stations were not retrieved for both the data sets. In comparison, we observe a much higher percentage of retrieval (CDOM as well as $\mathrm{Chl}$ ) when using the "nearest neighbor" atmospheric correction scheme together with the Carder semianalytic algorithm (figures $4 \mathrm{a}$ and 4b). Although there was a high correlation between SeaWiFS derived and in situ measurements (figure 5a), SeaWiFS derived Chl was overestimated for all stations for the October 1997 image. For the 31st January 1998 SeaWiFS data, large overestimates of SeaWiFS-derived Chl were all associated with the central Bay stations (figure 5b). At all these stations, the bottom was visible, suggesting that bottom reflectance clearly contributed to the water leaving radiance that resulted in Chl overestimates. Previous studies (Stumpf et al 1999) have also indicated high reflectance due to bottom effects at the central region of the Bay in winter. The CDOM absorption field $\left(a_{g} 400\right)$ derived from SeaWiFS data for October 1997 and January 1998 (figures $4 \mathrm{a}$ and 4b) are compared to in situ CDOM absorption measurements at the same wavelengths (figures $6 \mathrm{a}$ and $6 \mathrm{~b}$ ). We observe that although they are well correlated, the SeaWiFSderived estimates of CDOM absorption underestimated in situ measurements for both images. These results suggest that the general parameters used in the Carder semianalytic algorithm may have to be tuned locally, i.e., for bio-optical conditions encountered in Florida Bay. Besides, the seasonal effect of bottom reflectance may also have to be accounted for in future bio-optical algorithms for the region.

In summary, these and previous results (Carder et al 1999; Hu et al 2002) indicate improved performance of the turbid-water atmospheric correction algorithm and the Carder semianalytic algorithm for chlorophyll estimates for CDOM-rich waters. The application of the turbid-water atmospheric correction or the aerosol propagation scheme provides important advantages as it can be applied to unknown water types such as estuaries or shallow waters where bottom reflection contributes to the visible bands. The use of the multi-waveband semianalytic algorithm enabled differentiation between Chl and CDOM in coastal waters. In specific regions such as the Florida Bay, the need to account for bottom reflectance (Lee et al 1994) and tuning of parameters used in the bio-optical algorithm will be necessary in order to improve estimates of $\mathrm{Chl}$ and CDOM. CDOM maps provide important information on salinity field especially in coastal waters where often there is conservative mixing. In coastal estuaries, these derived phytoplankton pigment and salinity distributions can be used for coastal management to monitor and predict the health of the ecosystem.

\section{Acknowledgements}

This work has been supported by the National Aeronautics and Space Administration (NASA Grants NAG-3446, NAG5-6448, NAS5-97128 and NAG5-10738). We thank two anonymous reviewers for their comments and suggestions.

\section{References}

Arnone R A, Martinolich P, Gould Jr. R W, Stumpf R and Ladner S 1998 Coastal optical properties using SeaWiFS; Ocean Optics XIV, Kailua-Kona, Hawaii, USA

Blough N V, Zafiriou O C and Bonilla J 1993 Optical absorption spectra of waters from the Orinoco river outflow: Terrestrial input of colored organic matter to the Caribbean; J. Geophys. Res. 98 2271-2278

Boyer J N, Fourqurean J W and Jones R D 1999 Seasonal and long-term trends in the water quality of Florida Bay (1989-1997); Estuaries 22 417-430

Carder K L, Hawes S K, Baker K A, Smith R C, Steward R G and Mitchell B G 1991 Reflectance model for quantifying chlorophyll $a$ in the presence of productivity degradation products; J. Geophys. Res. 96 20599-20611

Carder K L, Chen F R, Lee Z P, Hawes S K and Kamykowski D 1999 Semianalytic moderate-resolution imaging spectrometer algorithms for chlorophyll $a$ and absorption with bio-optical domains based on nitrate depletion temperatures; J. Geophys. Res. 104 5403-5421

D'Sa E J, Steward R G, Vodacek A, Blough N V and Phinney D 1999 Determining optical absorption of colored dissolved organic matter in seawater with a liquid capillary waveguide; Limnol. Oceanogr. 44 1142-1148

D'Sa E J, Zaitzeff J B and Steward R G 2000 Monitoring water quality in Florida Bay with remotely sensed salinity and in situ bio-optical observations; Int. J. Remote Sens. 21 811-816

D'Sa E J, Zaitzeff J B, Yentsch C S, Miller J L and Ives R 2002 Rapid remote assessments of salinity and ocean color in Florida Bay; In: The Everglades, Florida Bay, and Coral reefs of the Florida Keys: An ecosystem sourcebook (eds) J W Porter and K G Porter (Boca Raton, FL: CRC Press) Chapter 15

Ding K and Gordon H R 1995 Analysis of the influence of $\mathrm{O}_{2}$ $A$-band absorption on atmospheric correction of oceancolor imagery; Appl. Opt. 34 2068-2080

Fourqurean J W and Robblee M B 1999 Florida Bay: A history of recent ecological changes; Estuaries 22 345-357

Garver S A and Siegel D A 1997 Inherent optical property inversion of ocean color spectra and its biogeochemical interpretation: I. Time series from the Sargasso sea; $J$. Geophys. Res. 102 18607-18625

Gordon H R, Brown J W and Evans R H 1988 Exact Rayleigh scattering calculations for use with the Nimbus7 Coastal Zone Color Scanner; Appl. Opt. 27 862-871

Gordon H R and Wang M 1994 Retrieval of water-leaving radiance and aerosol optical thickness over the oceans with SeaWiFS: a preliminary algorithm; Appl. Opt. 33 443-452

Hooker S B, Esaias W E, Feldman G C, Gregg W W and McClain C R 1992 An overview of SeaWiFS and ocean color; NASA Tech. Memo. 104566, vol. 1 (eds) S B Hooker and E R Firestone, NASA Goddard Space Flight Center, Greenbelt, Maryland, pp. 25 plus color plates. 
Hu C, Carder K L and Muller-Karger F E 2000 Atmospheric correction of SeaWiFS imagery of turbid coastal waters: a practical method; Remote Sens. Environ. 74 195-206

$\mathrm{Hu}$ C, Carder K L and Muller-Karger F E 2001 Erratum to "Atmospheric Correction of SeaWiFS imagery over turbid coastal waters: A practical method"; Remote Sens. Environ. 75447

Hu C, Muller-Karger F E, Biggs D C, Carder K L, Nababan B, Nadeau D and Vanderbloemen J 2002 Comparison of ship and satellite bio-optical measurements on the continental margin of the NE Gulf of Mexico; Int. J. Remote Sens. (in press)

Le Vine D M, Zaitzeff J B, D'Sa E J, Miller J L, Swift C and Goodberlet M. 2000 Sea surface salinity: Toward an operational remote-sensing system; In: Satellites, Oceanography and Society (eds) D Halpern (Elsevier Science B. V: Amsterdam) pp. 321-335

Lee Z, Carder K L, Hawes S K, Steward R G, Peacock T G and Davis C O 1994 Model for the interpretation of hyperspectral remote-sensing reflectance; Appl. Opt. 33 5721-5732

McClain C R, Evans R H and Darzi M 1995 SeaWiFS quality control masks and flags: initial algorithms and implementation strategy; NASA Tech. Memo. 104566, vol. 28 (eds) S B Hooker, E R Firestone and J G Acker, NASA Goddard Space Flight Center, Greenbelt, Maryland, pp. 38 plus color plates.

Morel A and Prieur L 1977 Analysis of variations in ocean color; Limnol. Oceanogr. 22 709-722

O'Reilly J E, Maritorena S, Mitchell B G, Siegel D A, Carder K L, Garver S A, Kahru M and McClain C R
1998 Ocean color chlorophyll algorithms for SeaWiFS; $J$. Geophys. Res. 103 24937-24953

O'Reilly J E et al 2000 Ocean color chlorophyll $a$ algorithms for SeaWiFS, OC2, and OC4: Version 4 In: SeaWiFS Postlaunch calibration and validation analyses, Part 3 (eds) S B Hooker and E R Firestone, NASA Tech. Memo. 206892, vol. 11, NASA Goddard Space Flight Center, Greenbelt, Maryland, pp. 9-23

Parsons T R, Maita Y and Lalli C M 1984 A manual of chemical and biological methods for seawater analysis (New York: Plenum) pp. 107-110

Phlips E J and Badylak S 1996 Spatial variability in phytoplankton standing crop and composition in a shallow inner-shelf lagoon, Florida Bay, Florida; Bull. Mar. Sci. $58203-216$

Ruddick K G, Ovidio F and Rijkeboer 2000 Atmospheric correction of SeaWiFS imagery for turbid coastal and inland waters; Appl. Opt. 39 897-912

Siegel D A, Wang M, Maritorena S and Robinson W 2000 Atmospheric correction of satellite ocean color imagery: the black pixel assumption; Appl. Opt. 21 3582-3591

Stumpf R R, Frayer M L, Durako M J and Brock J C 1999 Variations in water clarity and bottom albedo in Florida Bay from 1985 to 1997; Estuaries 22 431-444

Tassan S 1994 Local algorithms using SeaWiFS data for the retrieval of phytoplankton, pigments, suspended sediment, and yellow substance in coastal waters; Appl. Opt. 33 2369-2377

Tilmant J T 1989 A history and an overview of recent trends in the fisheries of Florida Bay; Bull. Mar. Sci. 44 3-22 